\title{
Learners' Participation in Informal Japanese-English Internet Chat
}

\author{
Sarah Pasfield-Neofitou
}

Monash University

\begin{abstract}
It has been widely claimed that computer mediated communication offers unique opportunities for language learners, including the ability to take on the roles of 'writer' and 'reader', 'teacher' and 'learner'. Hence, it is important for teachers and learners to be aware of not only the linguistic and interactional characteristics of especially bilingual chat, but also how participants in an intercultural setting may switch between roles. Learning about one's second language from a peer, and in turn, teaching that peer about one's native language may allow both participants opportunities to develop as language experts. This article utilises naturalistic bilingual chat data and follow-up interviews to examine the implications of these findings for learners, teachers and researchers.
\end{abstract}

\section{Keywords}

CMC, SLA, bilingual, chat

\section{Introduction}

The spread of the Internet has led to an increase in its use for educational purposes both inside and outside the classroom. Throughout the developed world, language students are now able to communicate with their peers in a target-language speaking country from almost anywhere, at any time. Accordingly, it has been widely claimed that computer mediated communication (CMC) including synchronous or 'real time' electronic chat programs such as 'MSN Messenger', where users compose text-based messages to one another, offer unique opportunities for language learners. ${ }^{1}$ These opportunities include the ability to communicate relatively cost-effectively with native speakers, despite geographic separation, both from inside the classroom and from home. This is of particular importance to students of Japanese as a Foreign Language (JFL) who may find opportunities to meet native-speaking peers difficult or impossible otherwise, yet there is a real lack of research on students' out-of-classroom communication using

1 MSN Messenger is a chat program distributed for free by the Microsoft Corporation. It has now been re-branded 'Windows Live Messenger'. Downloads are available in a number of languages from http://get.live.com/messenger/overview. 
CMC. Furthermore, few studies to date have employed introspective methodology like the follow up interview to attain greater ecological validity by providing insight into 'offscreen' activity and thought processes.

One of the main themes reiterated throughout particularly the early literature on synchronous CMC is the 'egalitarian' nature of chat. This often-cited benefit of 'equal participation' is based on the fact that synchronous CMC has what are perceived as 'fairer' rules that govern turn-taking than face-to-face communication, as the turns of all participants are treated as equal by the regulating software. ${ }^{2}$ Yet the simple fact that a learner's message is received and displayed on the screen by the computer does not mean that it is read and valued by their interlocutor. Furthermore, while the regulating software may treat each utterance the same, participation is highly influenced by the participant's computer literacy (including typing speed), Internet connection speed, and many personal factors, such as their relationship with their chat partner, the way in which the interlocutors frame the activity of chatting, and the individual roles they adopt in the course of communication.

It is argued by many researchers that the 'egalitarian' nature of chat is the cause of increased language usage, particularly among shyer participants. For example, Kelm found that computer-aided class discussion increased the language use of learners of Portuguese. ${ }^{3}$ This finding was supported by Kern, who discovered that chat offered more frequent opportunities for student expression than face-to-face interaction. ${ }^{4}$ Kern also found that students' language output was of a more sophisticated level in chat than in face-to-face discussion on the same topic, in terms of morphosyntactic features and the variety of discourse functions.

Warschauer also tested the claim that CMC can result in more equal participation among learners than face-to-face discussion, by studying the interaction of advanced ESL students in a Hawaiian university. ${ }^{5}$ The four quietest members of the class in the face-to-face discussions, all Japanese, increased their production almost ten-fold, going from $1.8 \%$ of all utterances to $17.3 \%$. This result appears very encouraging for learners who experience shyness in face-to-face situations.

While early work concentrated on statistics, in terms of the number of utterances or features produced, researchers have become increasingly interested in

\footnotetext{
2 Kelm, 'The Use of Synchronous Computer Networks in Second Language Instruction: A Preliminary Report', pp. 441 - 545; Kern, 'Restructuring Classroom Interaction with Networked Computers: Effects on Quantity and Characteristics of Language Production', pp. 457 - 76; Warschauer, 'Comparing Face-to-Face and Electronic Communication in the Second Language Classroom', pp. 7 - 26.

3 Kelm, op. cit.

4 Kern, op. cit.

5 Warschauer, op. cit.
} 
identity and participant roles, especially within sociocultural approaches. Among others, Herring has investigated power issues and turn taking in CMC, particularly in regards to gender stereotypes. ${ }^{6}$ Abrams compared the participant roles of students of intermediate German in classroom-based writing and CMC discussion, and found that learners adopted a wider variety of roles in the CMC discussions. ${ }^{7}$ Attacker, challenger, joker and supporter were all roles found in the class-based CMC discussions, but not in the group journals students jointly composed.

The body of work carried out on tandem learning via CMC is also relevant to the examination of teacher/learner roles in chat. Drawing on Sociocultual Theory, Chung, Graves, Wesche and Barfurth undertook a longitudinal case study of the Korean- and English-speaking peers studying each others' languages who were paired up for the purpose of language learning. ${ }^{8}$ It was found that participants took turns in the roles of 'expert' and 'novice', engaging in reciprocal teaching, supporting one another's language learning. Kötter also examined online tandems, observing a mandatory language exchange between classes at a German and North American university. ${ }^{9}$ In order to ensure successful tandem learning, Kötter argues that it is important for each partner to be prepared to adopt the role of 'expert' for their linguistic and cultural community.

Despite recognition of the importance of participant roles in CMC tandem learning and the multitude of opportunities CMC provides for authentic communication with native speakers outside the classroom, it is unclear how effectively learners adopt these roles outside the institutional sphere. It appears that little research has been conducted to examine the different roles adopted by students 'in the wild', away from teachers and the classroom, and the ways that their framing of the activity influences conversational outcomes when conversing with native speakers. Furthermore, despite the multitude of claims that one of the Internet's main benefits is increased support for autonomous study and language acquisition outside the classroom, there is a lack of empirical evidence to support this claim. Very little research has been conducted of naturalistic settings, outside the classroom, where learners are free to interact with whomever they choose, in the language of their choice, rather than being paired with a fellow learner or subject. In fact, Tudini found that some students engaged in learner-only chat in the classroom complained that they wanted "someone they could learn from". ${ }^{10}$ Accordingly, the aim of this

\footnotetext{
6 Herring, 'Gender and Democracy in Computer-Mediated Communication'; Herring (ed.), Computer-Mediated Communication: Linguistic, Social and Cross-Cultural Perspectives. Pragmatics and Beyond; Herring, 'Interactional Coherence in CMC'; Danet and Herring, 'Introduction'.

Abrams, 'Computer-Mediated Communication and Group Journals: Expanding the Repertoire of Participant Roles', pp. 489-503.

Chung et al., 'Computer-Mediated Communication in Korean-English Chat Rooms: Tandem Learning in an International Languages Program', pp. 49 - 86.

Kötter, 'Negotiation of Meaning and Codeswitching in Online Tandems', pp. 145 - 72.

10 Tudini, 'Using Native Speakers in Chat', pp. 141 - 63.
} 
paper is to investigate the in situ out-of-classroom patterns of chat participation of Japanese and English second-language learners in naturalistic settings, in the form of two research questions:

1. What role shifts between, for example, teacher and learner, do learners' patterns of CMC use indicate?

2. What factors influence who dominates the conversation?

In order to obtain a naturalistic picture of students' out-of-class bilingual online communication, no restrictions were placed upon the participants in this study. They were free to use chat at home, on campus, indeed, from any location, and to converse with a native-speaking peer of their choice (former host sister, classmate, language exchange partner), whenever and about whatever they like, and in whatever language they like.

\section{Research Methodology}

\section{Participants}

Five advanced students of Japanese (four female one male), enrolled in the top two (out of six) levels of Japanese language at an Australian university volunteered to participate in this study. Each had in-country experience in Japan, and had used chat in the past. All five Australian students are native speakers of English. In turn, they were each asked to invite the participation of a Japanese native speaker with whom they regularly used chat. All of the Japanese participants (four female one male) were native speakers of Japanese, advanced users of English (with eight to 14 years prior study), and had visited Australia. All five also had prior chat experience. It is important to note that, unlike many previous studies, the Japanese participants in this study were not fellow students that the Australians had been paired with by the researcher, but were friends and acquaintances of the Australian participants, with whom they had established relationships prior to the commencement of this study.

A total of ten participants participated in this study. Each pair had an established relationship prior to the commencement of data collection. Kaylene and Ruriko were language exchange partners at the same university, Phia and Soichiro were former classmates and kept in contact via chat after Soichiro returned to Japan, Jacob and Miku were social chatters who met through a mutual friend online, Evelyn and Azusa were former host sisters after Evelyn participated in a high-school exchange, 
and Nadia and Tomi were education students at the same university who met through Tomi’s flatmate. All names given are pseudonyms.

\section{Data collection}

At the time of data collection, MSN Messenger was the most popular instant messaging (chat) program in both Japan and Australia. Australian participants were asked to set the program to automatically record their chat conversations over the course of a month. The files created by this recording are called chat logs, and record the date, time, sender and recipient, as well as the content, of each message (see Figure 1).

\begin{tabular}{|c|c|c|c|c|}
\hline Date & Time & From & To & Message \\
\hline $5 / 02 / 2006$ & $11: 00: 04 \mathrm{PM}$ & Everyday Seraph & $\begin{array}{c}\text { Soichiro@ } \\
\text { Tsukuba }\end{array}$ & $\begin{array}{c}\text { こんばんは! } \\
((\text { Good evening!) })\end{array}$ \\
\hline $5 / 02 / 2006$ & $11: 00: 46 \mathrm{PM}$ & $\begin{array}{c}\text { Soichiro@ } \\
\text { Tsukuba }\end{array}$ & Everyday Seraph & $\begin{array}{c}\text { こんばんわ! 元 } \\
\text { 気にてます } \\
\text { か? } \\
\left(\begin{array}{c}\text { (Good evening! } \\
\text { Are you well? }))\end{array}\right.\end{array}$ \\
\hline
\end{tabular}

Figure 1. Sample excerpt from chat log from MSN Messenger between Phia (Everyday Seraph) and Soichiro, with English translation.

The process required to save chat conversations is relatively unobtrusive, taking only a matter of seconds. Furthermore, most participants were already using this feature, and several pairs including Kaylene and Ruriko, Evelyn and Azusa, and Phia and Soichiro were able to provide the researcher with chat logs dating back to before the commencement of the research project. Such archived records are particularly important, as they can aid in uncovering to what extent any 'observer effect' may have occurred once participants were conscious that their conversations would be analysed. No major differences in terms of language use, participant roles, and so on were found between the chat logs recorded prior to the recruitment process, and those recorded during the data collection period. It is important to note that while participants were unaware at the time of these earlier chat conversations that their communication would later be analysed, all data was provided voluntarily, and the participants were fully aware of the aims and procedures of the research project before any data was collected from them.

The earliest data obtained was from Phia and Soichiro, giving a total data collection period of almost five months for this pair. A total of 10 chat conversations were 
recorded by participants and provided to the researcher (three from each of Kaylene and Ruriko and Evelyn and Azusa, two from Phia and Soichiro, and one conversation from the other two pairs).

At the end of the one-month period, the Australian participants emailed the chat logs produced from their conversations with their Japanese partners to the researcher for discussion and analysis. Of the chat logs collected, one consisted of an attempted conversation, in which Evelyn tried, and failed, to get Azusa to participate. Follow-up interviews were conducted with both the Japanese and Australian participants in order to gain insight into participants' off-screen behaviour during the chat conversation. A follow-up interview with each Japanese participant was conducted via chat within minutes of their most recent interaction with their Australian chat partner. The chat log from this conversation was then kept for analysis also. As soon as possible after the follow-up interview with the Japanese participant, sometimes immediately after, sometimes the next morning in the case of a late night chat, a face-to-face follow-up interview was conducted with the Australian participant. Interviews were digitally recorded in wav format, and a back up was recorded simultaneously. Interviews were then transcribed using simplified Conversation Analysis conventions.

According to Nunan, introspection is the process of observing and reflecting upon one's mental state. ${ }^{11}$ A follow-up interview, as defined by Neustupný, is an interview ideally conducted immediately after the recording session, in which each participant is interviewed separately, and asked a set of questions to help establish their awareness of various processes, and as such, can only reveal processes of which the participants are aware. ${ }^{12}$ A further set of questions concerning the particulars of language use by the participant or their interlocutor was also asked. Accordingly, the follow-up chat interview conducted with the Japanese participants consisted of two sections, general questions on the participant's chat usage and English study, and specific questions on the most recent chat interaction. Stimulated recall, an introspective method where the participant can refer to a record of their interaction while describing their thought processes at the time of the activity was used in the second section of the chat interview. ${ }^{13}$ Segments of the chat log were produced, by cutting and pasting from the original chat log, and questions adapted from the guidelines of Neustupný and Miyazaki were asked. ${ }^{14}$ Questions in this section of the interview were of a very general nature, ranging from 「どう感じましたか」(“How did you feel?”) to 「どう思いまし たか?」 ("What did you think?”). The face-to-face follow-up interview with the

1 Nunan, Research Methods in Language Learning.

12 Neustupný, 'The Follow-up Interview', pp. 31 - 33.

13 Gass and Mackey, Stimulated Recall Methodology in Second Language Research.

14 Neustupný and Miyazaki, Gengo Kenkyū No Hōhō (Techniques for Language Research). 
Australian participants consisted of the same general questions about the participants' chat usage and Japanese study, then the interviewee was shown a printed copy of their most recent chat log, about which questions again based on Neustupný, and Neustupný and Miyazaki were asked.

\section{Analysis Method}

The methodology employed draws upon the framework of Thorne's examination of French language CMC use. ${ }^{15}$ As discussed above, the primary sources of data for this study consist of transcribed spoken texts (the follow-up interviews) and written texts (the chat logs from both the dyadic chat interactions and the chat follow-up interviews). The first, historical section of the follow-up interviews was analysed using Sociocultural Theory as the overall interpretative framework. The term sociocultural refers to a marriage of social and cultural factors, but Sociocultural Theory (SCT) invokes a specific association with the cultural-historical work of Lev Vygotsky, the influential Russian psychologist who put forward the key concepts of the Zone of Proximal Development, scaffolding, psychological tools and mediation, and internalisation. ${ }^{16}$ The goal of sociocultural research is to understand the relationship between human mental functioning and cultural, historical and institutional setting. A vital feature of Vygotsky's view of learning is that it is embedded in social and interactional events within the environment, such as the chat conversations examined in the present study.

Sociocultural Theory, and in particular the branch Activity Theory, emphasises that learning is the product of social interaction, and that higher, culturally constructed forms of thinking are reliant upon mediation. Vygotsky first advanced a model of mediated action which included the subject, their object of activity, and the artefact, or mediating tool. Later, Engeström proposed a more complex model to capture societal as well as cultural dimensions, such as communities, the rules that structure them, and the division of labour. ${ }^{17}$ The division of labour refers to both the horizontal actions and interactions among the members of the community and the vertical divisions of power and status, for example between teachers and students. Division of labour and power will be referred to in this sense in the present study.

Engeström's model is reproduced below (see Figure 2) ${ }^{18}$, infixed with the specifics of the present study. At the base of this model, the social framework of human activity

15 Thorne, 'An Activity Theoretical Analysis of Foreign Language Electronic Discourse'.

16 Vygotsky, Thought and Language; Vygotsky, Mind in Society; Vygotsky, 'The Development of Higher Forms of Attention in Childhood.

17 Engeström, 'Activity Theory and Transformation'.

18 Ibid., p. 31. 
is depicted, while the upper part represents Vygotsky's original conceptualisation of mediated goal directed activity. In Engeström's structure of a human activity system, the uppermost level of activity is driven by an object related motive, the middle level, action, by a conscious goal, and the bottom level consists of automatic operations driven by the conditions and tools of the action at hand.

Mediating artefacts Computers

Internet

English and Japanese languages
Subject Australian \& Japanese chat participants

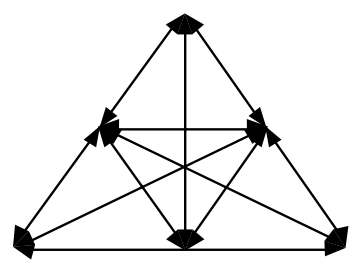

Community Pairs Other communities
Rules Rules of chat Individual rules established by pairs

\section{Object \\ Communication \\ Language learning \\ Division of}

Labour

Pair positions

Other positions

FIGURE 2. Engeström's Activity System, infixed with the specifics of the present study.

Sociocultural Theory is useful in interpreting the interviews in terms of participants' individual histories and social backgrounds as they relate to their communicative practices. Meanwhile, the participants' communicative activity (as recorded in the chat logs and informed by the second section of the interview) was analysed using a modified version of Sacks, Schegloff and Jefferson's Conversation Analysis, as advanced by Thorne. ${ }^{19}$

The unit of analysis utilised for the micro analysis of the chat logs was the 'e-turn', coined by Thorne. 'E-turns' are derivative of a turn unit, as defined by Sacks, Schegloff and Jefferson ${ }^{20}$. While a turn may be defined as ending each time the floor is transferred from one participant to another, in the context of MSN Messenger, or similar instant messengers, an 'e-turn' is a distinct block of text that is tagged with the sender's name (see Figure 3). 


\begin{tabular}{|c|c|c|c|}
\hline $28 / 04 / 2006$ & 11:13:33 PM & Nadia & $\begin{array}{l}\text { ああ そうですか。 何をべんきょうし } \\
\text { ていますか。 } \\
\text { ((Ah really? What are you studying?)) } \\
\end{array}$ \\
\hline $28 / 04 / 2006$ & 11:15:53 PM & Stomi $\delta$ & $\begin{array}{l}\text { 今は、bridging courseで勉強をしていて、 } \\
7 \text { 月から、TESOLのDIPLOMAを勉強する } \\
\text { 予定です。 } \\
\text { ((Now, I'm studying a bridging course, and from } \\
\text { July I plan to study for a TESOL diploma.)) }\end{array}$ \\
\hline $28 / 04 / 2006$ & 11:16:45 PM & $\delta$ tomi $\delta$ & $\begin{array}{l}\text { bridging courseは、大学院に入るための } \\
\text { fundamental courseです } \\
\text { ((The bridging course is a fundamental course in } \\
\text { order to enter graduate school. }))\end{array}$ \\
\hline $28 / 04 / 2006$ & 11:17:45 PM & Nadia & $\begin{array}{l}\text { ああ 分かります。私も モナッシュで } \\
\text { 勉強しています。日本語とESLの先生にな } \\
\text { りたいです。今Diploma of Education を勉 } \\
\text { 強してます。 } \\
\text { ((Ah I see. I am also studying at Monash. I want } \\
\text { to become a teacher of Japanese and ESL. Now, } \\
\text { I'm studying a Diploma of Education.)) }\end{array}$ \\
\hline
\end{tabular}

FIgURE 3. Example of a turn and an e-turn in a conversation between Nadia and Tomi.

In this way, a single turn may consist of more than one e-turn. Often, chat users may break a lengthy turn into a series of brief e-turns in order to maintain the interest of their interlocutor. An e-turn is completed by hitting either the 'send' button or the 'enter' key after typing an utterance.

\section{Analysis}

\section{Turn-taking and Conversational Strands Management}

Turn management is one of the fundamental rules of chat conversation. The supposed lack of turn-taking competition in chat has been claimed as evidence of its egalitarianism. Researchers such as Kitade, ${ }^{21}$ Toyoda and Harrison, ${ }^{22}$ Fujiike, ${ }^{23}$ and Fitze,${ }^{24}$ have claimed that turn-taking competition in chat does not occur because overlaps and interruptions are impossible. However, in MSN Messenger, like other chat programs, the order of turns is influenced by the respective typing speed of the participants, the connection speed of their computers, and the way in which the program receives and orders input.

\footnotetext{
1 Kitade, 'L2 Learners' Discourse and SLA Theories in CMC: Collaborative Interaction in Internet Chat', pp. 143 - 66.

2 Toyoda and Harrison, 'Categorization of Text Chat Communication between Learners and Native Speakers of Japanese', pp. 82 - 99.

3 Fujiike, 'Collaborative Interaction in EFL Web-Based Debates: How Do Learners Develop Socially Constructed Knowledge?'.

24 Fitze, 'Discourse and Participation in ESL Face-to-Face and Written Electronic Conferences', pp. 67 - 87.
} 
Furthermore, participants' sociocultural backgrounds, as revealed in the follow-up interview, also influence turn-taking and conversational dominance. Thus, the order of turns can sometimes become jumbled, where adjacency pairs, even if typed in that order, do not necessarily appear adjacent on the screen. For this reason, it appears important that chat participants utilize strategies for managing e-turns.

In the example below, the participants manage three different strands or threads of conversation simultaneously. The lines labelled ' 1 ' and joined by the grey solid line according to Kaylene, are "talking about the camera", in which Kaylene organised with her Japanese language exchange partner Ruriko via chat to use the Internet to contact friends and family in Japan using a webcam at Kaylene's house. The second topic, labelled ' 2 ' and joined by the black solid line, is about it being "so cool how they can email phones in Japan", and the final topic, labelled ' 3 ' and joined by the grey dotted line, is organising a day and time to use the webcam. While all of the topics are related, the turn adjacency is interrupted, with answers to questions, responses to comments and queries about statements delayed, occurring one to two turns later (see Figure 4).

\begin{tabular}{|c|c|c|}
\hline Time & From & Message \\
\hline $18: 23: 03 \mathrm{PM}$ & kay miró & Is that enough time to let people in Japan know you'll be online? \\
\hline $28: 23: 19 \mathrm{PM}$ & kay miró & oh, I forgot... you can email their phone, right? \\
\hline $38: 23: 25 \mathrm{PM}$ & 瑠璃子 & あ、母の日だけど仕事ある？？ \\
\hline & $(($ Ruriko $))$ & ((Ah, it's Mother's Day but do you have work??)) \\
\hline $28: 23: 41 \mathrm{PM}$ & kay miró & かつこいいね \\
\hline & & $(($ It's cool $))$ \\
\hline $18: 24: 03 \mathrm{PM}$ & 瑠璃子 & yes!! maybe it is ok!! \\
\hline $28: 24: 14 \mathrm{PM}$ & 瑠璃子 & What is cool?? \\
\hline 3 8:24:17 PM & kay miró & いいえ、バイトはあしたと土曜日だけ:) \\
\hline & & $(($ No, my part time job is only on tomorrow and Saturday :) )) \\
\hline $28: 24: 32 \mathrm{PM}$ & kay miró & being able to email people’s phones is cool $\wedge \wedge$; \\
\hline 3 8:24:57 PM & 瑠璃子 & Oh, nice!! So what time are you free?? \\
\hline $28: 25: 01 \mathrm{PM}$ & 瑠璃子 & Ah, I got it!! \\
\hline 3 8:25:34 PM & kay miró & anytime you like. I'll probably just being doing homework that day. \\
\hline
\end{tabular}

FIGURE 4. Turn management in language exchange partners Kaylene and Ruriko's chat. 
Kaylene described her management of turns, commenting, "I'm just so used to doing that in chat, because in English, I do that all the time as well, and sometimes we have three conversations going at the same time". She explained that "it's because typing takes a long time, and generally, while the other person's reading, you're saying something else anyway, and so, you end up replying to a comment, then typing one out, then replying to one". She also commented on the short-lived nature of these multiple and concurrent conversational strands, stating that "they don't usually last long anyway".

\section{Avoidance of Multiple Conversational Strands and Conversational Dominance}

The management of multiple and concurrent conversational strands did not occur in all conversations. Jacob described how he avoids multiple "streams of conversation" in chat, by monitoring the space at the bottom of the chat window, which would display "Miku is typing a message" when his partner was composing a turn. "I'd go to write something in, but it would say underneath, Miku is typing, and so I'd go, oh, okay, and delete what I was going to say, because I'd wait for her response". "Because often when... you're both... starting off a question, it'll get really confusing. So I thought, it's probably easier, just to have one stream of conversation going".

In the example below, Jacob began composing another e-turn to complete his turn, directly after his "your english is great" message, but noticed that Miku was typing, deleted his response, and waited almost two whole minutes to read what she had written, in an effort to avoid multiple streams or strands of conversation occurring.

\begin{tabular}{|l|l|l|}
\hline Time & From & Message \\
\hline 10:08:00 PM & Mr Enclosed & your english is great \\
\hline 10:09:59 PM & Miku & $\begin{array}{l}\text { my english has been gettin worse every year!! i did plitical } \\
\text { philosophy last semester n i bought lots of books related to } \\
\text { the subject, but i didnt understand at all even in japanese!! }\end{array}$ \\
\hline 10:09:59 PM & Miku & $\begin{array}{l}\text { 日本語難 しい } \\
\text { ((Japanese is difficult)) }\end{array}$ \\
\hline
\end{tabular}

FIGURE 5. Avoidance of multiple strands in social chatters Jacob (Mr. Enclosed) and Miku’s chat.

It is clear that while it may be impossible to interrupt a chat partner mid e-turn, it is certainly possible to interrupt the flow of conversation mid-turn, between two e-turns. Furthermore, not only is overlap possible in that both participants may compose a message at the same time, when the chat program displays the announcement, "Miku is typing a message" or similar, it is possible for participants 
to not only notice that overlap is occurring, but to make use of overlap avoidance strategies. Participants' use of these strategies are only apparent through use of the follow-up interview.

When one partner, like Miku, is prepared to manage multiple strands, and the other partner, like Jacob, is actively avoiding multiple strands by monitoring this announcement area on the screen, an imbalance in participation can occur. For this reason, consideration of the nature of a pair's relationship is crucial in analysis. Social chatters Jacob and Miku displayed the biggest discrepancy in terms of e-turns produced, as Jacob reported that he would wait for Miku to finish typing, but Miku would not wait for him. Thus, in their chat conversation Jacob composed and sent only 74 turns (an average of 0.75 turns per minute), in comparison with Miku's 124 (or 1.25 turns per minute), as shown in the table below. Pairs in which both partners reported avoiding multiple and concurrent strands, such as education students, Nadia and Tomi, and former classmates, Phia and Soichiro, were much more balanced in terms of turn-taking. In their conversation, Nadia took 24 turns, an average of 0.4 per minute, and Tomi 19 turns, or 0.32 per min. Phia and Soichiro each took seven lengthy turns in their first conversation, while in their second conversation, Phia took 27 turns, an average of 0.55 per minute, while Soichiro took 35 , an average of 0.71 per minute. They exhibited the slowest pace, producing the lowest number of turns per minute, but on average their turns were much longer (an average of 56.62 characters per turn in their two conversations, compared to the overall average of 26.73 characters per turn). Pairs in which both partners actively managed multiple and concurrent strands, such as language exchange partners Kaylene and Ruriko, and former host sisters Evelyn and Azusa, were also more fair in number of turns taken. Evelyn and Azusa also exhibited a much higher number of turns per minute, which suggests that the style of turn management is directly related to amount of turns participants produce.

\begin{tabular}{|l|l|l|l|l|l|l|l|l|l|l|l|}
\hline & \multicolumn{3}{|l|}{$\begin{array}{l}\text { Education } \\
\text { Students }\end{array}$} & \multicolumn{3}{l}{ Language Exchange } \\
Partners
\end{tabular}




\begin{tabular}{|l|l|l|l|l|l|l|l|l|l|l|}
\hline $\begin{array}{l}\text { MEAN TURNS } \\
\text { PER MINUTE }\end{array}$ & $\mathbf{0 . 7 2}$ & $\mathbf{1 . 1 9}$ & $\mathbf{2 . 0 6}$ & $\mathbf{2 . 1 8}$ & $\mathbf{2 . 0 6}$ & $\mathbf{5 . 4 5}$ & $\mathbf{1 . 0 3}$ & $\mathbf{1 . 9 9}$ & $\mathbf{0 . 3 9}$ & $\mathbf{1 . 2 5}$ \\
\hline English NS & 0.40 & 0.54 & 0.92 & 0.97 & 1.07 & 5.45 & 0.65 & 0.75 & 0.20 & 0.55 \\
\hline Japanese NS & 0.32 & 0.64 & 1.14 & 1.21 & 0.99 & 0.00 & 0.37 & 1.25 & 0.20 & 0.71 \\
\hline $\begin{array}{l}\text { MEAN } \\
\text { CHARACTERS } \\
\text { PER TURN }\end{array}$ & $\mathbf{2 1 . 7 9}$ & $\mathbf{2 7 . 9 9}$ & $\mathbf{2 7 . 4 3}$ & $\mathbf{3 0 . 4 8}$ & $\mathbf{7 . 1 6}$ & $\mathbf{3 . 6 7}$ & $\mathbf{1 3 . 4 1}$ & $\mathbf{2 2 . 2 5}$ & $\mathbf{6 0 . 7 9}$ & $\mathbf{5 2 . 4 5}$ \\
\hline English NS & 21.50 & 33.72 & 34.33 & 34.90 & 7.92 & & 3.67 & 12.06 & 50.57 & 49.30 \\
\hline Japanese NS & 22.16 & 23.15 & 21.91 & 26.91 & 6.33 & & 0.00 & 15.78 & 71.00 & 54.89 \\
\hline
\end{tabular}

FIGURE 6. Number of turns, length of chat in hours and number of characters.

\section{Participant Roles and the Division of Labour}

In intercultural Internet chat conversations, turn-taking may be viewed in terms of the sociocultural concept of a division of labour, as participants complete the actions of both writing and reading messages. In addition, many participants took up the role of the 'teacher', and engaged in reciprocal teaching. In one example, Ruriko asked Kaylene, "What is lol??". Kaylene provided her with the explanation that "lol is an acronym, it means Laugh Out Loud", then continued with an explanation of its usage, "Like the smiley face :) only laughing". The roles of expert and novice are reversed when Kaylene asks Ruriko about the origin of 「なるへそ」(naruheso, I see), which Kaylene believes to be a regional dialect form of 「なるほじ」(naruhodo, I see). Ruriko confirms Kaylene's understanding of the meaning, but explains that it is a littleused "slang" term rather than dialect. She goes on to say in English "It is not formal expression, but it has humor!!".

As the imbalances in turn taking discussed above suggests, there was also sometimes an imbalance in the division of labour. In the language exchange partners pair, where the nature of Kaylene and Ruriko's tandem-like relationship was one based upon the mutual goal of teaching and learning of a second language, the division of labour was fairly even. Both partners produced a similar number of turns, thus the burden of composing and responding to messages was reasonably equal. Furthermore, both Kaylene and Ruriko experienced role shifts from teacher to learner, asking one another questions about language. Instead of only asking about new words directly related to the communication at hand, Kaylene and Ruriko, as language exchange partners, took turns to ask explicit questions on language. Ruriko stated in the chat interview that she and Kaylene knew each other primarily as language exchange partners. In the face-toface interview, Kaylene added that Ruriko often asks her about English phrases "that she wants to try and use, and isn't sure about how to use them". 
One pair in which the division of labour was certainly not even was the former host sisters, Evelyn and Azusa. Evelyn stayed as an exchange student at Azusa's home in Japan in 2002 on a one-year student exchange. In her interview, Evelyn described having difficulty in gaining Azusa's attention in chat, and revealed that a large portion of her e-turns were specifically aimed at spiking Azusa's interest. Evelyn went to great efforts to maintain Azusa's interest in the conversation, typing her messages in English, even though she wanted to practice her Japanese, because she knew that Azusa enjoyed speaking English, and attempted to use this tactic to lure her into a conversation. Whenever she felt Azusa's attention waning, Evelyn would code-switch back to English, stating in her interview "I didn't want to lose her". One of the chat logs Evelyn submitted for the study was a failed example of her attempting to entice Azusa into chat conversation, where Azusa appeared online, but did not respond to any of Evelyn's utterances. In the chat log reproduced below, Evelyn's use of English to gain Azusa's attention is evident (see Figure 7). Although she begins in Japanese, Evelyn's last-ditch effort, over a minute later, having had no response, to get Azusa to chat with her, is in English. As participants were not interviewed on this early chat, it is impossible to tell whether Azusa was knowingly logged in to MSN Messenger and ignored Evelyn, or did not realise Evelyn was trying to attract her attention. However, Evelyn did refer to this failed attempt in the interview, and stated that it was her reason for utilising the strategy of starting the next conversation in English. Evelyn and Azusa also did not engage in the teacher-learner role swapping and reciprocal learning that language exchange partners Kaylene and Ruriko did. Evelyn described in her interview how she felt that her Japanese was inadequate compared with Azusa's level of English, and revealed that she would type new words into her dictionary "rather than asking her, what does that mean, because it's just easier”. For the majority of her interaction with Azusa, Evelyn's primary goal was to maintain Azusa's cooperation in a social conversation, an inequality in interaction reflecting their unequal relationship.

\begin{tabular}{|l|l|l|l|l|}
\hline Date & Time & From & To & Message \\
\hline $9 / 05 / 2006$ & $12: 30: 54$ & Wallaby & 梓 & $\begin{array}{l}\text { 梓 } ! \\
((\text { Azusa! }))\end{array}$ \\
\hline $9 / 05 / 2006$ & $12: 30: 54$ & Wallaby & 梓 & $\begin{array}{l}\text { 元気? } \\
((\text { How are you? }))\end{array}$ \\
\hline $9 / 05 / 2006$ & $12: 31: 27$ & Wallaby & 梓 & hello? \\
\hline
\end{tabular}

Figure 7. Evelyn's (Wallaby) attempted conversation with Azusa.

Where one partner produced considerably more e-turns, or lengthier e-turns, than the other, a vertical power relationship was formed, whereby one partner took on the role of the reader, and the other, of the writer. The majority of the chats contained 
slightly more Japanese than English, and accordingly, the Japanese native speakers composed and sent the majority of the e-turns. The vertical relationship produced when one speaker took on or was given the identity of the 'native speaker' is evident in Jacob's waiting for Miku to finish, Evelyn's attempts to maintain Azusa's interest, and Phia's casting of herself as the 'listener', as she reported in the interview. It is important to note that it is not always the partner who produces the highest volume of text that holds the most power. Azusa wielded power in her contact with Evelyn by being non-responsive. Furthermore, Phia commented in her interview that in chats with her former classmate, Soichiro, she made efforts to "indulge him" in topics that seemed to interest him, and stated, "I was just listening to the story". Education student Nadia reported waiting ten minutes for her chat partner, Tomi, to say goodbye to her, and stated an hour later in the interview "I felt a bit sad", and "I thought it was rude" that she did not respond. Nadia later reported that she and Tomi never contacted each other again.

\section{Multitasking and Ignoring}

In addition to the personal relationships between the interlocutors, a number of other technological and sociocultural factors influenced participant's levels of participation. While using online chat in this study, all except one of the participants were multitasking - completing between two and four activities simultaneously. On the computer, these activities included writing, chatting with others in separate chat windows, writing emails to other friends, consulting an online dictionary for assistance in the conversation at hand, surfing the web (for assistance in the conversation or for leisure), playing games, listening to music, and even using PowerPoint for work, or Word for study. Real world concerns also interrupted participant's online activity. Participants left conversations to go to the bathroom, and one participant, Jacob, carried out a face-to-face conversation in English with his father on the same topic as his online conversation with Miku in Japanese at the same time.

Participants engaged in multiple activities simultaneously were often more distracted, and hence less attentive, than the participants who were concentrating solely on the conversation at hand. In the case of the education students, Tomi explained that she was writing an email to a friend, as well as chatting to someone besides Nadia in a separate window. When Nadia said goodbye, Tomi simply concentrated on her second chat window, while Nadia waited for ten minutes, staring at the screen, for Tomi to say a formal goodbye. Chatting with multiple interlocutors also influenced language choice, as many users had difficulty switching between the Japanese and English orthography input methods, using either the keyboard or mouse. Phia described great frustration about not knowing the keyboard shortcuts to switch between Japanese and English, 
and commented that if she started in one language, she tried to use that language for as long as possible, so that the conversation would not be interrupted by her cumbersome orthographic switching method. So although she was highly motivated to practice her Japanese, and was one of only two participants who identified language learning as a goal, Phia used primarily English in her conversations with Soichiro if she was simultaneously chatting with an English speaker in another window. In turn, this then meant that Phia was the 'native speaker' in their primarily English conversation, and Soichiro shouldered the bulk of the labour in terms of decoding Phia's turns.

Other learners found that engaging in multiple activities at once was actually beneficial to their conversation and their language learning. More than half of the ten participants reported using either online or electronic dictionaries while chatting to assist their conversation and language acquisition, and one Australian student even completed her homework while chatting with her Japanese chat partner. Those students who did not use dictionaries often had extenuating circumstances (such as Miku, the social chatter who had lent her dictionary to a friend). The two main types of reference sources used were electronic dictionaries (5/10 participants) and online dictionaries (3/10 participants). Electronic dictionaries are small hand-held computers, similar in size to a calculator, which contain integrated reference materials, often including a Japanese monolingual, Japanese-English, English-Japanese, and an in-depth kanji dictionary. Online dictionaries are usually free to use, searchable dictionaries accessible via the Internet. Two of the participants, Nadia and Kaylene, used multiple sources, a combination of electronic and online dictionaries.

Online dictionaries were found to have several advantages over electronic dictionaries, firstly, in confirming the readings of kanji. Nadia revealed in her interview that she used the dictionary web site Rikai after her failed attempt to use her friend's electronic dictionary, to look up the readings of kanji sent by her chat partner and fellow education student, Tomi. Nadia looked up 遠い (far) and spent two minutes looking up 職業 (occupation) simply to confirm that her own readings of the pronunciation were correct, which they were. While checking the pronunciation was not directly relevant to the conversation, it was relevant to Nadia's primary goal of language learning. However, Nadia did not check her understanding of the meaning of 遠い, which was incorrect, at least at the time of interview. Nadia believed the meaning was 'close', rather than 'far'. While this appears to be a missed opportunity for learning, it did not impair her ability to answer the question「そこは遠いんですか？？」 (Is that far??) as she answered in terms of type of transportation required and time needed, rather than a binary yes / no answer, which may have resulted in miscommunication. Kaylene, on the other 
hand, only used the online Jim Breen's dictionary ${ }^{25}$ to discover the readings of kanji she did not know, such as 憧れ (yearned for) and 鶴 (crane). Jacob, too, kept Jim Breen's dictionary open throughout his chat with Miku, "just in case" but decided not to use it for time reasons, commenting that as his chat partner seemed keen he "didn't want to cause a lull in the conversation".

It appears that activities such as consulting a dictionary or surfing the web may contribute to the flow of the conversation and provide opportunities for language learning, while disruptive activities like chatting with someone else or concentrating on an email may interrupt the flow of conversation, and cause one's interlocutor to feel neglected. However, as Jacob noted, even consulting a dictionary can cause a lull in the conversation, while one partner waits for the other to look up a word. In these cases, pairs such as the language exchange partners Kaylene and Ruriko often found it beneficial to ask their partner the meaning of a word rather than using a dictionary, while Jacob preferred changing the topic altogether. Jacob often avoided topics that showed signs of developing communication difficulty. When Jacob confused the name of his chat partner Miku's home town, rather than repair, he commented in the interview that he decided to "get out of there" by changing the topic to the weather. In another situation, Jacob said that he was not sure whether Miku thought that he had quit the band or that the band had stopped, after he sent 「バンド止めました」 (stopped band). Although Jacob was unaware as to the source of the misunderstanding he perceived, he stated in the interview "my reaction, again, was get out of there! Something's not going right in the conversation, change topic". Jacob stated he was afraid that "if we'd kept talking about it, that it would have popped up again", and this formed his reason for avoiding the topic altogether, and instead complimenting Miku on her display picture.

In many cases, interviews revealed that participants were unsatisfied with the help provided by their electronic dictionaries for two main reasons. Firstly, the usage of electronic dictionaries varies considerably from model to model. Nadia, the education student, used a friend's electronic dictionary, which was unfamiliar to her, and she reported that it "didn't work", instead, opting to use an online dictionary for the remainder of her conversation with Tomi. Secondly, electronic dictionaries often contain formal language, with little or no explanation of use. This can cause two kinds of problems, firstly, when looking up slang terms. Ruriko also tried using an electronic dictionary, to look up 'hardcore', however, the meaning that the electronic dictionary gave,がんこな (stubborn) did not fit with her language exchange partner Kaylene’s slang usage of the term (dedicated). Instead, Ruriko relied upon Kaylene's explanation. Secondly, electronic dictionaries can often suggest overly formal language that does

25 http://www.csse.monash.edu.au/ jwb/cgi-bin/wwwjdic.cgi?1C. 
not fit with the sociocultural context of an informal chat. Soichiro, while chatting with his former classmate, Phia, used his electronic dictionary to look up 鎖骨(clavicle), yet after Soichiro's repeated use of the word 'clavicle', Phia said it amused her because "that's a word I probably wouldn't know, until I broke it!". She noted that "Where he uses clavicle, instead, we would use collarbone, that's, I guess, something that you wouldn't find in a dictionary, clavicle you would". This is not to say that electronic dictionaries do not have their advantages also. Kaylene stated that she used her electronic dictionary a lot, and that while chatting, she used it to look up the spelling of Japanese words, such as 一緒に (together), when she forgot whether it contains a double consonant sound (isshoni) or not (ishoni). Evelyn relied upon her electronic dictionary rather than asking her chat partner and former host sister Azusa, because it was "easier".

Overall, completing more than one task simultaneously was common among the participants, and only Nadia, the least experienced chatter, did not engage in multitasking. While participants showed high levels of skill in managing multiple conversations, and even multiple streams of conversation within several of their dyadic conversation windows at once, sometimes their partners reported feeling ignored or unheard. In a fast-paced chat, messages may scroll off-screen quite rapidly, and there is a danger that some messages may disappear unread. Furthermore, a student who stops to consult their dictionary may find that they have missed a large portion of the conversation by the time they discover the word they were originally searching for. In most cases, participants may have benefited from asking their chat partner the meaning of a word rather than looking it up in the dictionary, both to save time, and because the informal nature of chat means that many of the words that are unfamiliar to students are not included in the dictionary, or are included in a more formal sense. However, in order for participants to feel comfortable asking one another questions, they need to have first established a good relationship. Evelyn, who had a lengthy but troubled relationship with her partner Azusa, and Jacob, who had only recently met Miku online, reported that they did not feel comfortable in asking their partners questions. In particular, Evelyn not only felt that her Japanese was inferior to Azusa's English, but that she was indebted to her former host sister, and hence did not want to bother Azusa with too many questions about Japanese.

\section{Conclusions}

The research described in this paper provides insight into learners' participation in CMC with native speakers outside the classroom or computer laboratory. It was found that although participants may in theory have the same opportunities to participate, their actual participation is highly dependent upon numerous social and technical factors, 
including their language level, relationship with their interlocutor, computer dexterity, typing speed, and the demand of other tasks they may be completing concurrently, among others. This suggests that outside the classroom, the benefits of chat such as increased participation and egalitarianism, which may be present in teacher or researcher-led classroom experiments, is dependent upon the way in which the participants perceive the activity of chat, their goals, and the ways in which they choose to organise their interaction, and should not be viewed as a naturally occurring feature. It also suggests that the style of turn management is directly related to the amount of turns participants produce, with those who manage multiple strands producing a higher number of turns.

Furthermore, the simple production of an utterance does not guarantee that the receiver reads or even notices the message sent. It is highly possible for participants to accidentally skip over a turn in a fast-paced chat conversation, or to consciously ignore what is being said. It was found that several pairs had unbalanced interaction, often rooted in a social problem or chat style, and in these pairs, one participant often felt unvalued and unheard, or even inferior. While it is impossible to speculate as to whether participants' online communication was more equal than their face-to-face interaction in my own study, as face-to-face data was not collected, the point made is that even if $\mathrm{CMC}$ is branded as more equal, it would be dangerous to assume that it is 'egalitarian'. So although there appears to be a general consensus in much of the literature that chat and instant messaging can provide increased opportunities to participate in interaction, more research is required to discover what factors influence some participants to take up these opportunities.

While it is evident that roles adopted and levels of participation in chat vary and are related to the goals, relationships, and perceived relative linguistic competence of participants, chat may provide valuable opportunities for second language socialisation and language learning. As language exchange partners Kaylene and Ruriko demonstrate, relatively equal levels of participation and language use, teamed with a goal of reciprocal teaching and learning can afford both participants opportunities to take on the role of reader or writer, learner or teacher. Furthermore, this kind of role swapping allows both participants opportunities to develop as language experts, both in their native language, and in their second language. Future study would be needed to evaluate the extent to which the roles adopted or distribution of turns in chat used for language practice would affect second language acquisition. 
New Voices Volume 3

\section{References}

Abrams, Z. I., 'Computer-mediated communication and group journals: expanding the repertoire of participant roles', System, 29 (2001), pp. 489-503.

Chung, Y. G., Graves, B., Wesche, M. and Barfurth, M., 'Computer-Mediated Communication in Korean-English Chat Rooms: Tandem learning in an international languages program', The Canadian Modern Language Review/La Revue canadienne des langues vivantes, 62/1 (2006), pp. 49 - 86.

Danet, B. and Herring, S. C., 'Introduction', The Multilingual Internet: Language, Culture, and Communication Online (Oxford: Oxford University Press, 2007), pp. 1 - 39.

Engeström, 'Activity Theory and Transformation', in Engeström, Y., Miettinen, R., and Punamäki, R. L. (eds.), Perspectives on Activity Theory (Cambridge: Cambridge University Press, 1999), pp. 19 - 38.

Fitze, M., 'Discourse and Participation in ESL Face-to-Face and Written Electronic Conferences', Language Learning \& Technology, 10/1 (2006), pp. 67 - 87.

Fujiike, T., 'Collaborative Interaction in EFL Web-Based Debates: How do learners develop socially constructed knowledge?', CALL-EJ Online 5:2 (2004).

Gass, S. M. and Mackey, A., Stimulated Recall Methodology in Second Language Research (Mahwah: Lawrence Erlbaum Associates, 2000).

Herring, S. C., 'Gender and Democracy in Computer-Mediated Communication' The Electronic Journal of Communication / La Revue Electronique de Communication 3:2 (1993). Retrieved 7 October 2006, from http:// www.cios.org/EJCPUBLIC/003/2/00328.HTML.

Herring, S. C. (ed.), Computer-Mediated Communication: Linguistic, Social and Cross-Cultural Perspectives. Pragmatics and Beyond (Philadelphia: Benjamins, 1996).

Herring, S. C., 'Interactional Coherence in CMC', Proceedings of the 32nd Hawai'i International Conference on System Sciences (HICSS-32) (Hawai'i: IEEE Computer Society Press, 1999), pp. 1 - 13.

Kelm, O., 'The Use of Synchronous Computer Networks in Second Language Instruction: A Preliminary Report', Foreign Language Annals, 25/5 (1992), pp. 441 - 545.

Kern, R. G., 'Restructuring Classroom Interaction with Networked Computers: Effects on Quantity and Characteristics of Language Production', The Modern Language Journal, 79/iv (1995), pp. 457 - 76.

Kitade, K., 'L2 Learners' Discourse and SLA Theories in CMC: Collaborative interaction in Internet chat', Computer Assisted Language Learning, 13/2 (2000), pp. 143 - 66.

Kötter, M., 'Negotiation of Meaning and Codeswitching in Online Tandems', Language Learning \& Technology, 7/2 (2003), pp. $145-72$.

Neustupný, J. V., 'The Follow-Up Interview', Japanese Studies Association of Australia, 10/2 (1990), pp. 31 - 33.

Neustupný, J. V. and Miyazaki, S., Gengo kenkyū no hōhō (Techniques for Language Research) (Tōkyō: Kuroshio Shuppan, 2002).

Nunan, D., Research Methods in Language Learning (Cambridge: Cambridge University Press, 1992). 